\title{
Validation of a Compact Motion Sensor for the Measurement of Physical Activity in Patients with Chronic Obstructive Pulmonary Disease
}

\author{
Akihito Sugino Yoshiaki Minakata Masae Kanda Keiichiro Akamatsu \\ Akira Koarai Tsunahiko Hirano Hisatoshi Sugiura Kazuto Matsunaga \\ Masakazu Ichinose \\ Third Department of Internal Medicine, Wakayama Medical University, Wakayama, Japan
}

\section{Key Words}

Activity of daily living • Chronic obstructive pulmonary disease $\cdot$ Monitoring $\cdot$ Repeatability $\cdot$ Reproducibility Validation study

\begin{abstract}
Background: The DynaPort Activity Monitor (DAM) has been reported to be useful to evaluate the activity in healthy subjects and patients with chronic obstructive pulmonary disease (COPD). However, it is difficult to estimate the activity of COPD patients using DAM, because its battery works only for several hours and sensors should be worn at two parts of the body. A newly developed compact, single-position triaxial accelerometer (Actimarker) can measure the activity for $>1$ month, but has not been validated for COPD patients. Objectives: The validity of the Actimarker was evaluated in COPD patients. Methods: In study 1, the validity of the device was tested in 14 stable COPD patients by comparing it with DAM. In study 2, the influence of the weather on activity was examined. In study 3 , the number of measurement days required to ensure repeatability was determined. Results: The durations of activity measured by the Actimarker and DAM were significantly correlated at intensity values $\geq 2.0, \geq 2.5$ and $\geq 3.0$ METs. The duration of activity on rainy days was significantly shorter than that on non-rainy days. The values of intraclass correlation coefficients were $>0.8$ in
\end{abstract}

3-, 4- or 5-day measurements, and there was no systematic bias at any number of days or intensities with Bland-Altman plots. Conclusions: The validity of the Actimarker was confirmed, and repeatability was obtained when the data from at least 3 non-rainy weekdays were analyzed. Actimarker appears to be useful as a simplified method to evaluate the physical activity of COPD patients.

Copyright $\odot 2011$ S. Karger AG, Basel

\section{Introduction}

Patients with chronic obstructive pulmonary disease (COPD) are much less active in daily life than healthy subjects, and the level of physical activity is reported to be related to the decline in lung function [1], to the number of hospitalizations [2,3] and to mortality [4]. Therefore, the physical activity of COPD patients has attracted increasing clinical interest and is considered an important parameter in the treatment of COPD [5].

Recently, motion sensors, especially accelerometers, have been used to quantify the physical activity of COPD patients [6-9] instead of questionnaires, which are less reliable [5, 10-12]. Among the reported accelerometers, the only well-validated accelerometer for COPD patients is the DynaPort Activity Monitor (DAM; McRoberts BV, The Hague, The Netherlands) [13-15]. However, it is dif-

\section{KARGER}

Fax +41613061234 E-Mail karger@karger.ch www.karger.com
(C) 2011 S. Karger AG, Basel

0025-7931/12/0834-0300\$38.00/0

Accessible online at:

www.karger.com/res
Yoshiaki Minakata

Third Department of Internal Medicine, Wakayama Medical University

811-1 Kimiidera Wakayama

Wakayama 641-0012 (Japan)

Tel. +81 73441 0619, E-Mail minakaty@ wakayama-med.ac.jp 
Table 1. Characteristics of the COPD patients for study 1

\begin{tabular}{|c|c|}
\hline Age, years & $74.3 \pm 6.2$ \\
\hline Males/females, $\mathrm{n}$ & $14 / 0$ \\
\hline Smoking history, pack-years & $77.0 \pm 30.4$ \\
\hline Current/ex-smokers, n & $1 / 13$ \\
\hline Body mass index & $20.7 \pm 3.4$ \\
\hline \multicolumn{2}{|l|}{ Pulmonary function } \\
\hline FVC, liters & $3.41 \pm 0.44$ \\
\hline $\mathrm{FEV}_{1}$, liters & $1.66 \pm 0.51$ \\
\hline $\mathrm{FEV}_{1} / \mathrm{FVC}, \%$ & $48.2 \pm 11.2$ \\
\hline $\mathrm{FEV}_{1}, \%$ of predicted & $64.0 \pm 19.8$ \\
\hline TLC, liters & $5.99 \pm 0.48$ \\
\hline FRC, liters & $2.47 \pm 0.48$ \\
\hline $\mathrm{RV}$, liters & $3.80 \pm 0.48$ \\
\hline IC/TLC & $0.33 \pm 0.07$ \\
\hline $\mathrm{DLCO}, \mathrm{ml} / \mathrm{min} / \mathrm{mm} \mathrm{Hg}$ & $11.12 \pm 3.82$ \\
\hline DLCO, $\%$ of predicted & $79.8 \pm 24.6$ \\
\hline $\mathrm{DLCO} / \mathrm{V}_{\mathrm{A}}, \mathrm{ml} / \mathrm{min} / \mathrm{mm} \mathrm{Hg}$ & $2.34 \pm 0.80$ \\
\hline $\mathrm{DLCO} / \mathrm{V}_{\mathrm{A}}, \%$ of predicted & $54.7 \pm 18.9$ \\
\hline$\Delta \mathrm{N}_{2}, \%$ & $3.42 \pm 1.82$ \\
\hline \multicolumn{2}{|c|}{$\begin{array}{l}\mathrm{FVC}=\text { Forced vital capacity; } \mathrm{FEV}_{1}=\text { forced expiratory volume } \\
\text { in } 1 \mathrm{~s} \text {; TLC = total lung capacity; } \mathrm{FRC}=\text { functional residual ca- } \\
\text { pacity; RV = residual volume; } \mathrm{IC}=\text { inspiratory capacity; } \mathrm{DLCO}= \\
\text { diffusing capacity for carbon monoxide; } \mathrm{V}_{\mathrm{A}}=\text { alveolar volume; } \\
\Delta \mathrm{N}_{2}=\text { the slope of phase } \mathrm{III} \text { in the single-breath nitrogen washout } \\
\text { test. Data are presented as means } \pm \mathrm{SD} \text {, unless otherwise indi- } \\
\text { cated. }\end{array}$} \\
\hline
\end{tabular}

ficult to estimate the activity of COPD patients using this apparatus, because the DAM battery works for only several hours, and the sensors are relatively large and should be worn at two parts of the patient's body (waist and left thigh).

A compact triaxial accelerometer, which is worn at only one part of the patient's body, has been used to measure the activity of COPD patients $[7,16]$. However, its reproducibility was only evaluated with questionnaire data but not with the data of the well-validated DAM [7]. The compact triaxial accelerometer, which is worn at one part of a patient's body and easy to handle, needs validation with data from a triaxial accelerometer such as the DAM.

Furthermore, though the duration of measurements was between 2 and 5 days in the previous reports $[7,14$, 17], it might be difficult to detect the patient-specific physical activity during such a small number of days. In order to detect the patient-specific physical activity, the activity should be measured for longer durations, and suitable conditions for analysis should be determined.

Recently, a new, very small triaxial accelerometer, the Actimarker (Panasonic, Osaka, Japan), has been de-
Table 2. Characteristics of the COPD patients for studies 2 and 3

$\begin{array}{lc}\text { Age, years } & 71.7 \pm 8.3 \\ \text { Males/females, } \mathrm{n} & 10 / 0 \\ \text { Smoking history, pack-years } & 75.4 \pm 20.4 \\ \quad \text { Current/ex-smorkers, } \mathrm{n} & 1 / 9 \\ \text { Body mass index } & 20.9 \pm 3.1 \\ \text { Pulmonary function } & \\ \mathrm{FVC} \text { liters } & 3.40 \pm 0.38 \\ \mathrm{FEV}_{1}, \text { liters } & 1.45 \pm 0.56 \\ \mathrm{FEV}_{1} / \mathrm{FVC}, \% & 41.9 \pm 13.2 \\ \mathrm{FEV}_{1}, \% \text { of predicted } & 54.5 \pm 23.4 \\ \mathrm{TLC}_{\text {liters }} & 6.31 \pm 0.67 \\ \mathrm{FRC}, \text { liters } & 4.16 \pm 0.78 \\ \mathrm{RV}, \text { liters } & 2.74 \pm 0.71 \\ \mathrm{IC} / \mathrm{TLC} & 0.29 \pm 0.07 \\ \mathrm{DLCO}, \mathrm{ml} / \mathrm{min} / \mathrm{mm} \mathrm{Hg} & 11.89 \pm 4.81 \\ \mathrm{DLCO}, \% \text { of predicted } & 81.4 \pm 33.0 \\ \mathrm{DLCO} / \mathrm{V}_{\mathrm{A}}, \mathrm{ml} / \mathrm{min} / \mathrm{mm} \mathrm{Hg} & 2.44 \pm 1.01 \\ \mathrm{DLCO} / \mathrm{V}_{\mathrm{A}}, \% \text { of predicted } & 56.6 \pm 24.5 \\ \Delta \mathrm{N}_{2}, \% & 3.52 \pm 1.60\end{array}$

$\mathrm{FVC}=$ Forced vital capacity; $\mathrm{FEV}_{1}=$ forced expiratory volume in $1 \mathrm{~s}$; TLC = total lung capacity; FRC = functional residual capacity; $\mathrm{RV}=$ residual volume; $\mathrm{IC}=$ inspiratory capacity; $\mathrm{DLCO}=$ diffusing capacity for carbon monoxide; $\mathrm{V}_{\mathrm{A}}=$ alveolar volume; $\Delta \mathrm{N}_{2}=$ the slope of phase III in the single-breath nitrogen washout test. Data are presented as means $\pm \mathrm{SD}$, unless otherwise indicated.

veloped. This accelerometer is worn only at the waist, is easy to handle, can monitor activity continuously for $>1$ month and can also evaluate the activity separately according to the intensity. In this study, in order to establish a simpler and well-validated method to monitor the physical activity of COPD patients, we tested the validity of the Actimarker compared to that of DAM. Then, we monitored the activity for 2 weeks and investigated the influence of weather on the duration of physical activity. Finally, we determined the minimal number of days for analysis to ensure the repeatability of the measurements. We also evaluated these studies separately according to the intensity of activity.

\section{Subjects and Methods}

\section{Subjects}

Outpatients with stable COPD without any other disease that might interfere with walking were recruited from the Wakayama Medical University Hospital. COPD was defined as postbronchodilator $\mathrm{FEV}_{1} / \mathrm{FVC}<0.7$. They had not been diagnosed with asthma or bronchiectasis [18]. The characteristics of the study patients have been listed in tables 1 and 2 . 
Informed consent was obtained from all participants, and the study was approved by the local ethics committee (Committee: Institutional Review Board of the Wakayama Medical University; project name: Study on the effect of medical intervention on the physical activity in COPD patients; approval number: 527).

Study Design

Study 1. To evaluate the validity of the Actimarker compared with the DAM, both an Actimarker and DAM were attached to 14 outpatients with stable COPD at the same time for $7 \mathrm{~h}$, from 10:00 a.m. to 5:00 p.m. Then, the duration of activity measured by the Actimarker at different intensities, >1.5, 2.0, 2.5 and 3.0 METs, and the duration of locomotion (walking and cycling) measured by DAM were monitored.

Study 2. In order to investigate the influence of the weather on the duration of physical activity, an Actimarker was attached to 10 outpatients with stable COPD throughout the day for 2 weeks, and the duration of activity on rainy days was compared with that on non-rainy days.

Study 3. In order to determine how many days of measurement are necessary to ensure the repeatability of the measurements, the same 10 subjects with stable COPD in study 2 were recruited. The duration of activity from 5 days was compared with that from 2 , 3 and 4 days. The repeatability was evaluated by intraclass correlation coefficient (ICC) and by Bland-Altman plots.

\section{Measurement of Activity}

Both the DAM and Actimarker are activity monitors. DAM consists of two accelerometer sensors that are worn at the waist and the left leg that can record the time spent walking, cycling, standing, sitting or lying for 7 consecutive hours. The Actimarker is a small $(74.5 \times 13.4 \times 34.0 \mathrm{~mm})$ and lightweight $(36.0 \mathrm{~g})$ accelerometer that is worn only at the waist and can continuously monitor for $>1$ month. The Actimarker collects data of triaxial acceleration at $20 \mathrm{~Hz}$, and the standard deviation of the data for $1 \mathrm{~min}$ is defined as the mean value of acceleration. The METs value is calculated from the linear regression formula produced by the relationship between the mean value of acceleration and the MET value measured using a respiratory gas metabolic system.

\section{Statistical Analysis}

Statistical analysis was performed using GraphPad Prism 5 (GraphPad Software, San Diego, Calif., USA). The relationship between the Actimarker and DAM and the influence of rainy days were assessed by regression analysis and the Wilcoxon signedrank test, respectively. $\mathrm{p}<0.05$ was considered significant $[19,20]$. Repeatability was evaluated by ICC, in which ICC $\geq 0.8$ is a generally accepted value for multiple ICCs in accelerometer studies $[17,21-23]$, and also by Bland-Altman plots, in which the mean values and differences between the two are plotted, and the systematic bias and limits of agreement (within mean \pm 2 SD of the differences) are obtained [19, 20].

\section{Results}

\section{Study 1}

A correlation between the duration of activity measured by the Actimarker and that of locomotion by DAM was recognized at intensities $\geq 2.0$ METs $(r=0.611, \mathrm{p}=$
$0.020), \geq 2.5$ METs $(r=0.731, p=0.003)$ and $\geq 3.0$ METs $(\mathrm{r}=0.697, \mathrm{p}=0.006)$, but not at an intensity $\geq 1.5$ METs $(r=0.236, p=0.417$; fig. 1$)$. A correlation between the duration of activity measured by the Actimarker and the movement intensity during movement by DAM was also recognized at intensities $\geq 2.0$ METs $(r=0.557, p=0.039)$, $\geq 2.5$ METs $(r=0.679, p=0.008)$ and $\geq 3.0$ METs $(r=$ $0.828, p=0.0003)$, but not at an intensity $\geq 1.5$ METs $(r=$ $0.352, \mathrm{p}=0.217)$.

\section{Study 2}

During the 2 weeks, the data of the first and last day were excluded from the analysis because the patients went to the hospital for the setup or removal of the Actimarker and could not be recorded for all of those days. Also, the data of weekend days or holidays were excluded because some patients had jobs on weekdays. One patient was excluded from the study because there was no rainy day during the 2 weeks. Accordingly, the data of 9 patients were finally analyzed. Among the evaluable 9 subjects, 2 subjects experienced 1 rainy day in 2 weeks, 2 subjects 2 rainy days, 4 subjects 3 rainy days, and 1 subject 4 rainy days. The duration of activity on rainy days was significantly shorter than that on non-rainy days at all intensities ( $\mathrm{p} \leq 0.05$; fig. 2).

\section{Study 3}

Among the measured 2 weeks, at least 5 non-rainy weekdays were obtained from all patients. The value of ICC for 2 days was $<0.8$ at an intensity $\geq 3.0$ METs, but the values of ICC for 3,4 or 5 days were $>0.8$ at all intensities of activity (fig. 3). The average bias (the range of $95 \%$ confidence intervals) of the difference between 2 and 5 days at intensities $\geq 2.0$ METs, $\geq 2.5$ METs and $\geq 3.0$ METs were 4.1 ( -6.4 to 14.6$), 2.2$ (-6.3 to 10.6 ) and 1.3 $(-2.3$ to 4.9$)$, respectively. Those between 3 and 5 days at $\geq 2.0, \geq 2.5$ and $\geq 3.0$ METs were 6.8 ( -0.2 to 13.8 ), 4.6 ( -0.5 to 9.8 ) and 0.9 ( -2.0 to 3.9 ), and those between 4 and 5 days were 1.6 ( -3.6 to 6.9$), 0.6$ ( -2.9 to 4.1$)$ and $-0.6(-2.6$ to 1.5), respectively. There was no systematic bias (fixed and proportional bias) for any number of days or intensities (fig. 4).

\section{Discussion}

We demonstrated the validity of the Actimarker compared with the DAM, which has already been well validated for the measurement of physical activity in COPD patients when activities >2.0, 2.5 and 3.0 METs were ap- 
Fig. 1. Correlation between Actimarker and DAM. The duration of locomotion measured by DAM is shown on the x-axis, and the duration of activity according to the intensity of activity measured by Actimarker is shown on the $y$-axis.
Fig. 2. Influence of rainy days. The durations of activity on rainy days and nonrainy days were compared by paired t test. Underlined values are medians of all data.
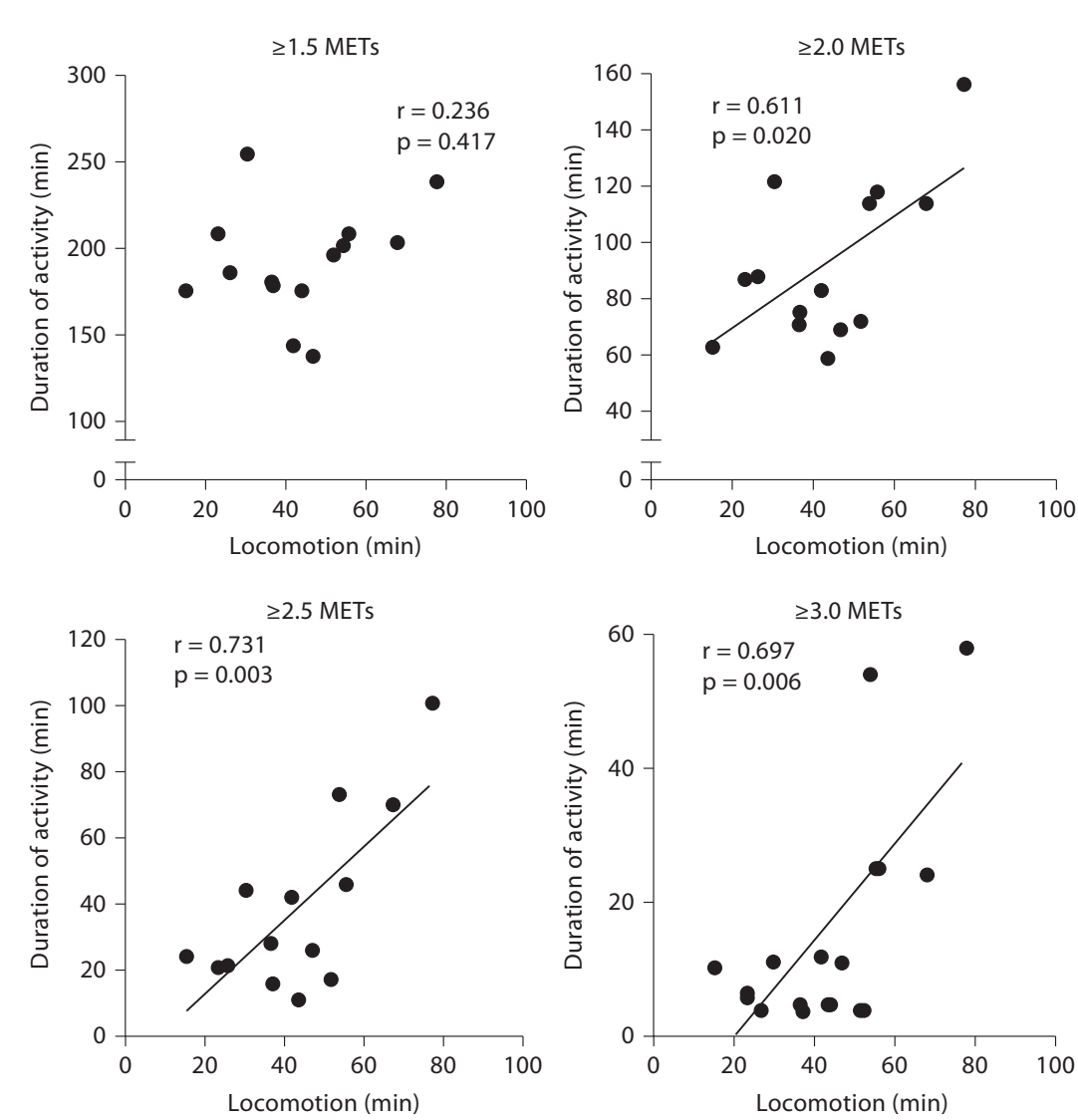

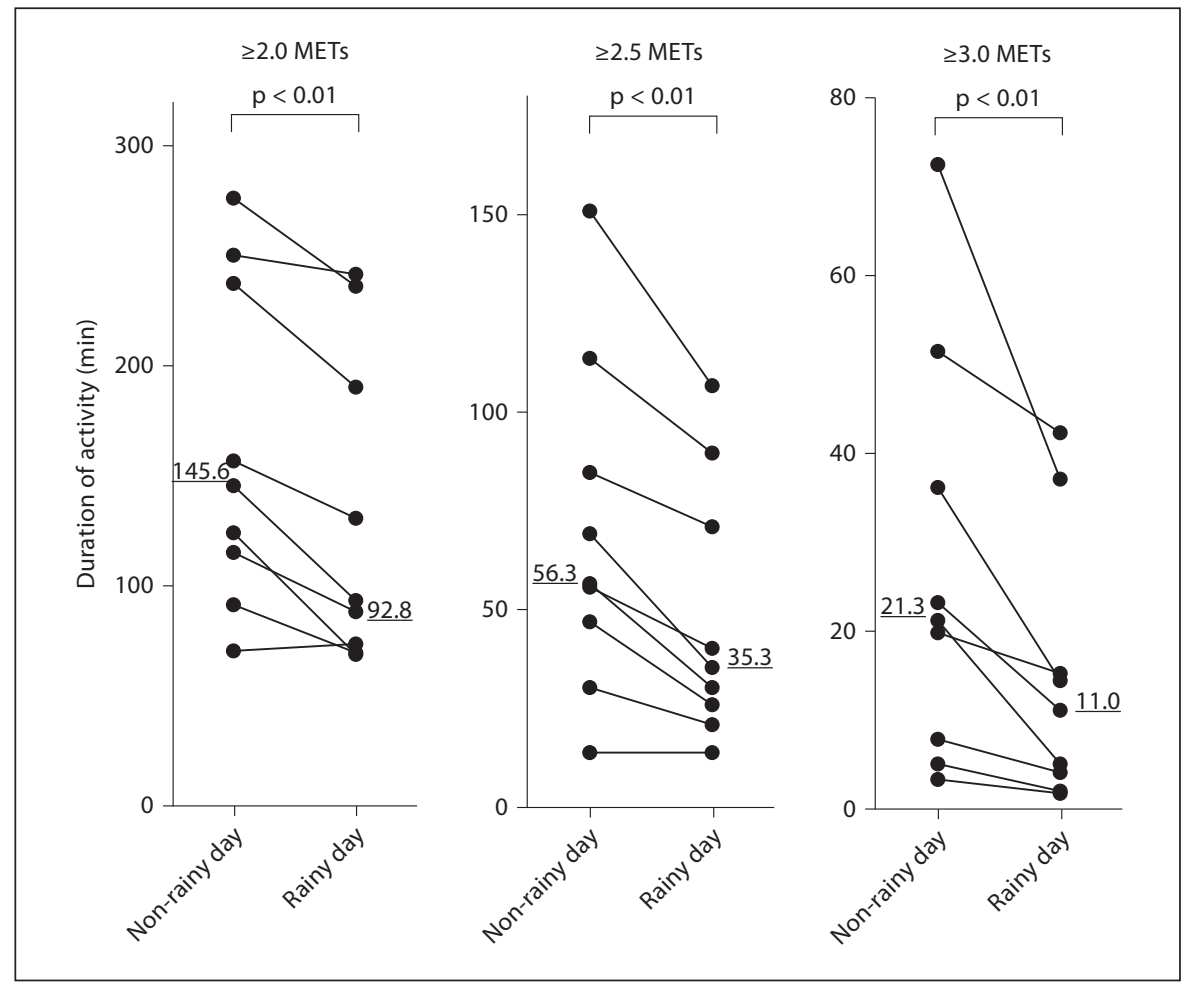

Validation of a Sensor for COPD Activity 
Fig. 3. Determination of the numbers of days for analysis by ICC. Numbers of days for analysis are shown on the $\mathrm{x}$-axis and values of the ICC are shown on the $y$-axis. A value of ICC $\geq 0.8$ indicates repeatability of the methods.

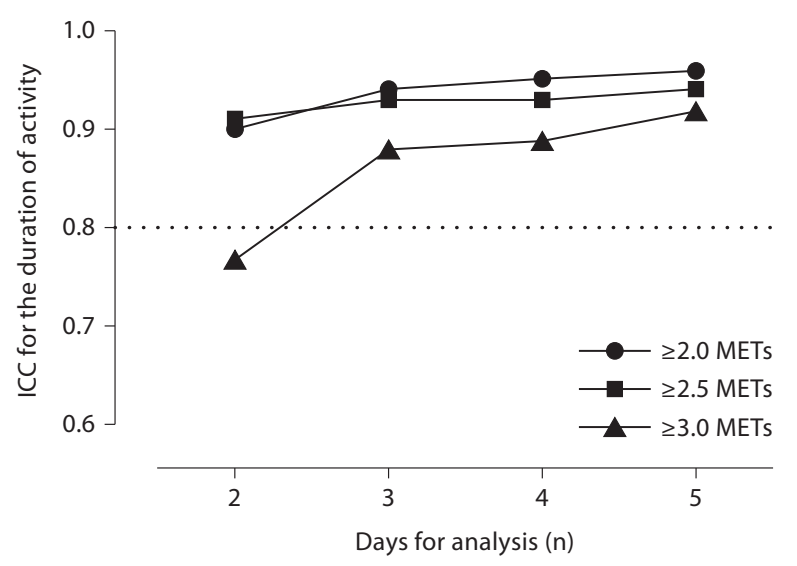

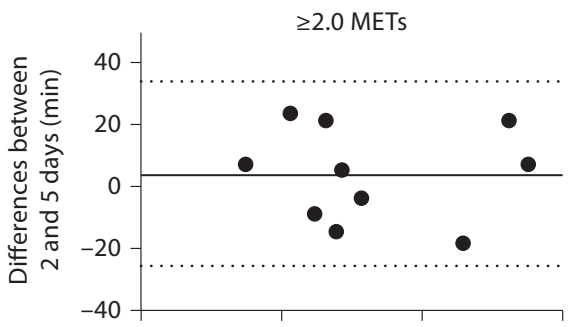
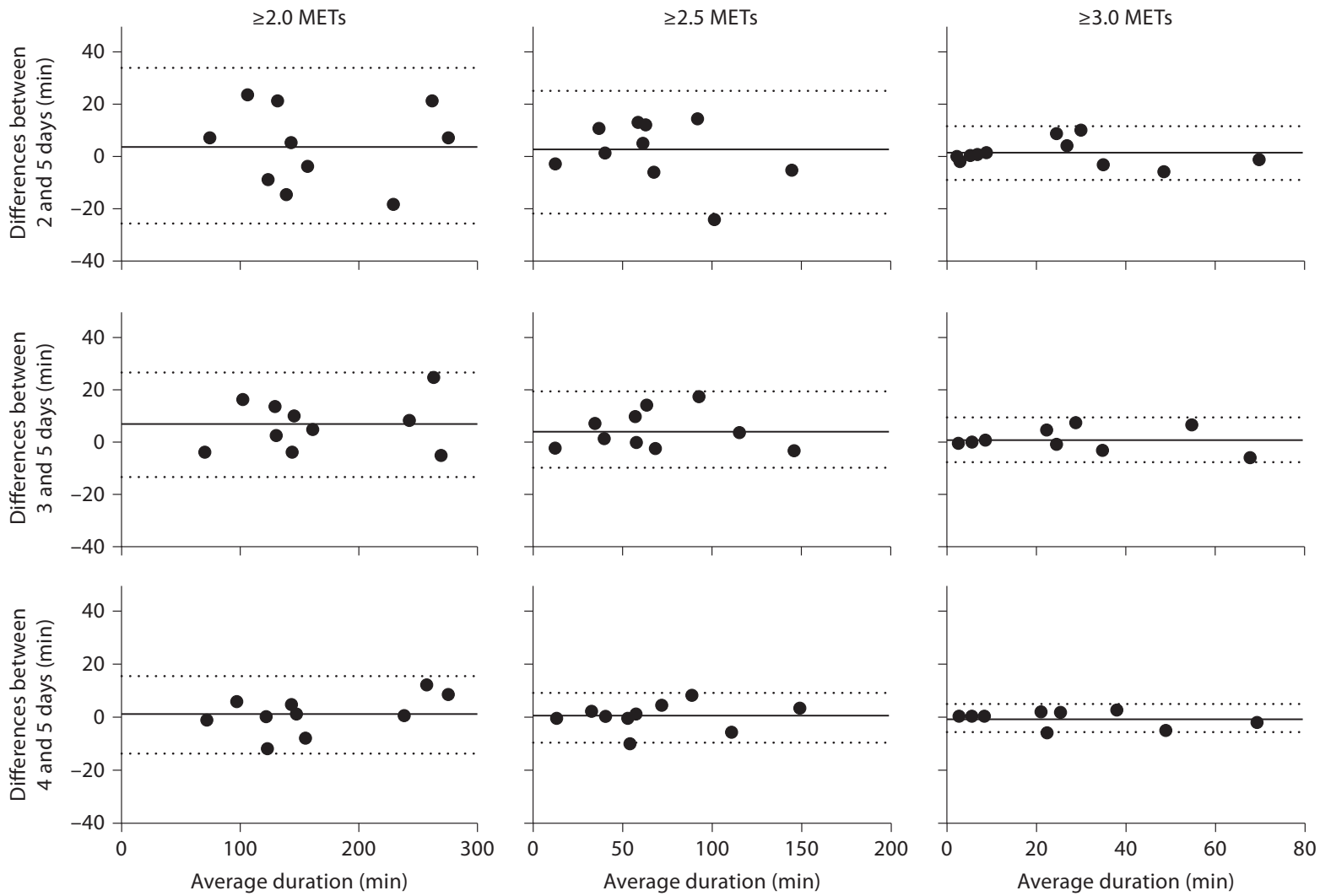

Fig. 4. Determination of the numbers of days for analysis by Bland-Altman plots. Average durations of activity from 2,3 or 4 days and those from 5 days are shown on the x-axis, and differences in the durations from 2, 3 or 4 days and those from 5 days are shown on the y-axis. Mean values of all data (solid lines) +2 SD (upper dashed lines) and -2 SD (lower dashed lines) are shown. 
plied. As the physical activity on rainy days was significantly decreased, the data from non-rainy days should be selected for the analysis. Furthermore, the repeatability of the measurements by the Actimarker was confirmed when the data were collected from 3 non-rainy weekdays. These validated results demonstrate that the Actimarker can be reliable for evaluating physical activity in COPD patients.

Generally, a triaxial accelerometer can more precisely detect three-dimensional movement than uni- or biaxial accelerometers, and an accelerometer worn at 2 parts of the body is more sensitive, although more difficult to deal with than that worn at a single part of the body. Most of the reported single-position accelerometers for the measurement of physical activity in COPD patients were uniaxial or biaxial $[8,17,24,25]$. Especially, SenseWear Pro Armband (Body Media, Pittsburgh, Pa., USA) has been frequently used for COPD $[8,17,25]$, but it is a biaxial accelerometer and its accuracy was somewhat poor [26]. A single-position triaxial accelerometer has been applied for COPD patients, but the validation of the method was performed by comparison with the data of questionnaires and not with DAM $[7,16]$, which could suggest that the validation for COPD patients was inadequate. Another single-position triaxial accelerometer, DynaPort Minimod (McRoberts BV) has been validated with DAM, but its size is $85 \times 50 \times 10 \mathrm{~mm}$ and its weight $70 \mathrm{~g}$, which is twice as heavy as the Actimarker, and there is only one report on its application for COPD patients [26]. As the activity of COPD patients measured by the Actimarker was reliable at intensities of $\geq 2.0, \geq 2.5$ and $\geq 3.0 \mathrm{METs}$, this could become a useful method to easily evaluate the activity of COPD patients.

In previous reports, measurements lasted from 2 to 5 days $[7,14,17]$, but it might not be adequate for the detection of patient-specific physical activity. In order to detect patient-specific physical activities, we measured the activity for 2 weeks and evaluated the conditions of the days to analyze the data. First, we excluded the data of weekend days and holidays and included only the data of weekdays, according to the report of Pitta et al. [14]. Tudor-Locke et al. [23] also reported that, since there was a significant difference in the activity duration on Sundays, Sunday should be the last day to enter in the analysis. These reports support our decision to select only weekdays. Steele et al. [7] showed that the amount of physical activity performed during weekdays or weekend days is similar among retired persons. As some patients in our study had jobs, the data of only weekdays were selected for analysis in our study.

Validation of a Sensor for COPD Activity
Secondly, the effects of weather should be considered. The duration of activity on rainy days was significantly shorter than that on non-rainy days. Although lower activity on rainy days would be plausible in COPD patients, it was proven for the first time in the current study. For the detection of patient-specific physical activity, the data of only non-rainy days were selected for the analysis.

Thirdly, the minimal number of days required for analysis should be determined. Both ICC and Bland-Altman plots have been used for the validation of methods to evaluate physical activity for several conditions [26$28]$. When the number of days for analysis was 2 , the ICC was $<0.8$ in the activity at intensities $\geq 3.0$ METs. However, when the number of days was 3,4 or 5 , the ICCs were $>0.8$ at all intensities and the repeatability was confirmed. Next, we compared the mean value of the duration of activity from 2, 3 or 4 days with those from 5 days by BlandAltman plots. There was no systematic bias for any number of days or intensities. These results suggest that the data of at least 3 days are necessary to confirm repeatability, which is compatible with other accelerometer studies for COPD patients [7, 17].

In the current study, we performed the validation of an accelerometer according to the intensity of activity for the first time. The MET intensity of physical activity was classified as follows: $<3.0$ METs as light, 3.0-6.0 METs as moderate and $>6.0$ METs as vigorous intensity [29]. The intensity of talking while sitting is considered 1.5 METs, talking while standing is 1.8 METs, walking very slowly $(<2.0 \mathrm{~m} / \mathrm{h})$ is 2.0 METs, and walking at normal speed $(2.5 \mathrm{~m} / \mathrm{h})$ is 3.0 METs [30]. Older adults aged $\geq 65$ years are recommended to practice moderate-intense aerobic physical activity [31]. The intensity of activity for COPD patients should be $\geq 2.0$ METs. When the duration of activity $\geq 2.0$ METs was divided into 2.0-2.5 METs (including 2.0 METs but excluding 2.5 METs), 2.5-3.0 METs and 3.0-3.5 METs, the mean duration of activity of each intensity was 186, 100 and 37 min, respectively. As activity of light intensity is predominant in COPD patients, the evaluation of such activity should be very important. As this Actimarker could evaluate physical activity at an intensity $\geq 2.0$ METs as well as $\geq 3.0$ METs, it should become a useful tool for evaluating physical activity of COPD patients.

There are several limitations that need to be addressed. First, the number of patients enrolled was small. Secondly, the subjects recruited in the present study were all males. Although Lopez Varela et al. [32] reported that women with COPD showed greater physical limitations than men, Torres et al. [33] reported that gender differ- 
ences in skeletal muscle characteristics were not found in COPD patients. The importance of the validation study, however, is the difference between the absolute activity and the measured activity. We, therefore, think the current results for men could also be applied to women. Thirdly, the comorbidities of COPD were not evaluated, though diseases which might interfere with walking were excluded. It has been reported that up to $25 \%$ of the population $>65$ years suffers from two comorbidities and up to $17 \%$ have three [34]. The validation of the Actimarker for COPD patients should therefore be applied for various types of COPD patients who have several comorbidities. Elucidation of the effects of comorbidity on the physical activity in COPD patients should be done in a future study.
In summary, the Actimarker was validated for evaluating the physical activity of COPD patients. The monitoring of 3 non-rainy weekdays was necessary to obtain repeatable measurements by the Actimarker. As the Actimarker is compact, easy to deal with and could monitor not only activity of moderate intensity but also that of light intensity, it could be useful as a simplified tool to evaluate physical activity of COPD patients.

\section{Acknowledgments}

The authors thank Mr. Manabu Nishigai for technical support and assistance with statistical analysis, and Mr. Brent Bell for reading the paper.

\section{References}

1 Garcia-Aymerich J, Lange $\mathrm{P}$, Benet $\mathrm{M}$, Schnohr P, Anto JM: Regular physical activity modifies smoking-related lung function decline and reduces risk of chronic obstructive pulmonary disease: a population-based cohort study. Am J Respir Crit Care Med 2007; 175:458-463.

2 Pitta F, Troosters T, Probst VS, Spruit MA, Decramer M, Gosselink R: Physical activity and hospitalization for exacerbation of COPD. Chest 2006;129:536-544.

$\checkmark 3$ Garcia-Aymerich J, Farrero E, Felez MA, Izquierdo J, Marrades RM, Anto JM: Risk factors of readmission to hospital for a COPD exacerbation: a prospective study. Thorax 2003;58:100-105.

4 Myers J, Prakash M, Froelicher V, Do D, Partington S, Atwood JE: Exercise capacity and mortality among men referred for exercise testing. N Engl J Med 2002;346:793-801.

5 Garcia-Aymerich J, Lange P, Benet M, Schnohr P, Anto JM: Regular physical activity reduces hospital admission and mortality in chronic obstructive pulmonary disease: a population based cohort study. Thorax 2006;61:772-778.

66 Schonhofer B, Ardes P, Geibel M, Kohler D, Jones PW: Evaluation of a movement detector to measure daily activity in patients with chronic lung disease. Eur Respir J 1997;10: 2814-2819.

7 Steele BG, Holt L, Belza B, Ferris S, Lakshminaryan S, Buchner DM: Quantitating physical activity in COPD using a triaxial accelerometer. Chest 2000;117:1359-1367.

$\checkmark 8$ Watz H, Waschki B, Boehme C, Claussen M, Meyer T, Magnussen H: Extrapulmonary effects of chronic obstructive pulmonary disease on physical activity: a cross-sectional study. Am J Respir Crit Care Med 2008;177: 743-751.
9 Pitta F, Takaki MY, Oliveira NH, Sant'anna TJ, Fontana AD, Kovelis D, Camillo CA Probst VS, Brunetto AF: Relationship between pulmonary function and physical activity in daily life in patients with COPD Respir Med 2008;102:1203-1207.

10 Pitta F, Troosters T, Probst VS, Spruit MA, Decramer M, Gosselink R: Quantifying physical activity in daily life with questionnaires and motion sensors in COPD. Eur Respir J 2006;27:1040-1055.

- 11 Esteban C, Quintana JM, Aburto M, Moraza J, Egurrola M, Perez-Izquierdo J, Aizpiri S Aguirre U, Capelastegui A: Impact of changes in physical activity on health-related quality of life among patients with COPD. Eur Respir J 2010;36:292-300.

12 Benzo RP, Chang CC, Farrell MH, Kaplan R, Ries A, Martinez FJ, Wise R, Make B, Sciurba F: Physical activity, health status and risk of hospitalization in patients with severe chronic obstructive pulmonary disease. Respiration 2010;80:10-18.

13 Pitta F, Troosters T, Spruit MA, Decramer M, Gosselink R: Activity monitoring for assessment of physical activities in daily life in patients with chronic obstructive pulmonary disease. Arch Phys Med Rehabil 2005;86: 1979-1985.

-14 Pitta F, Troosters T, Spruit MA, Probst VS Decramer M, Gosselink R: Characteristics of physical activities in daily life in chronic obstructive pulmonary disease. Am J Respir Crit Care Med 2005;171:972-977.

15 Pitta F, Troosters T, Probst VS, Lucas S, Decramer M, Gosselink R: Potential consequences for stable chronic obstructive pulmonary disease patients who do not get the recommended minimum daily amount of physical activity. J Bras Pneumol 2006;32: 301-308.
16 Garcia-Rio F, Lores V, Mediano O, Rojo B, Hernanz A, Lopez-Collazo E, Alvarez-Sala R: Daily physical activity in patients with chronic obstructive pulmonary disease is mainly associated with dynamic hyperinflation. Am J Respir Crit Care Med 2009;180: 506-512.

17 Watz H, Waschki B, Meyer T, Magnussen H: Physical activity in patients with COPD. Eur Respir J 2009;33:262-272.

18 Global initiative for chronic obstructive lung disease. Global strategy for the diagnosis, management, and prevention of chronic obstructive pulmonary disease 2009. www. goldcopd.com (accessed December 2010).

19 Bland JM, Altman DG: Statistical methods for assessing agreement between two methods of clinical measurement. Lancet 1986; i:307-310.

20 Bland JM, Altman DG: Comparing methods of measurement: why plotting difference against standard method is misleading. Lancet 1995;346:1085-1087.

21 Baranowski T, de Moor C: How many days was that? Intra-individual variability and physical activity assessment. Res Q Exerc Sport 2000;71:S74-S78.

22 Matthews CE, Ainsworth BE, Thompson RW, Bassett DR Jr: Sources of variance in daily physical activity levels as measured by an accelerometer. Med Sci Sports Exerc 2002; 34:1376-1381.

23 Tudor-Locke C, Burkett L, Reis JP, Ainsworth BE, Macera CA, Wilson DK: How many days of pedometer monitoring predict weekly physical activity in adults? Prev Med 2005;40:293-298. 
-24 Sewell L, Singh SJ, Williams JE, Collier R, Morgan MD: Can individualized rehabilitation improve functional independence in elderly patients with COPD? Chest 2005;128: 1194-1200.

-25 Hill K, Dolmage TE, Woon L, Goldstein R, Brooks D: Measurement properties of the SenseWear armband in adults with chronic obstructive pulmonary disease. Thorax 2010;65:486-491.

-26 Langer D, Gosselink R, Sena R, Burtin C, Decramer M, Troosters T: Validation of two activity monitors in patients with COPD. Tho$\operatorname{rax} 2009 ; 64: 641-642$.

-27 Crouter SE, Clowers KG, Bassett DR Jr: A novel method for using accelerometer data to predict energy expenditure. J Appl Physiol 2006;100:1324-1331.
8 Welk GJ, McClain JJ, Eisenmann JC, Wickel EE: Field validation of the MTI Actigraph and BodyMedia armband monitor using the IDEEA monitor. Obesity (Silver Spring) 2007;15:918-928.

29 Pate RR, Pratt M, Blair SN, Haskell WL, Macera CA, Bouchard C, Buchner D, Ettinger W, Heath GW, King AC, et al: Physical activity and public health. A recommendation from the centers for disease control and prevention and the American College of Sports Medicine. JAMA 1995;273:402-407.

30 Ainsworth BE, Haskell WL, Whitt MC, Irwin ML, Swartz AM, Strath SJ, O'Brien WL, Bassett DR Jr, Schmitz KH, Emplaincourt PO, Jacobs DR Jr, Leon AS: Compendium of physical activities: an update of activity codes and MET intensities. Med Sci Sports Exerc 2000;32:S498-S504.

-31 Nelson ME, Rejeski WJ, Blair SN, Duncan PW, Judge JO, King AC, Macera CA, Castaneda-Sceppa C: Physical activity and public health in older adults: recommendation from the American College of Sports Medicine and the American Heart Association. Med Sci Sports Exerc 2007;39:1435-1445.
2 Lopez Varela MV, Montes de Oca M, Halbert RJ, Muino A, Perez-Padilla R, Talamo C, Jardim JR, Valdivia G, Pertuze J, Moreno D, Menezes AM: Sex-related differences in COPD in five Latin American cities: the PLATINO study. Eur Respir J 2010;36:10341041.

33 Torres SH, Montes de Oca M, Loeb E, Mata A, Hernandez N: Gender and skeletal muscle characteristics in subjects with chronic obstructive pulmonary disease. Respir Med 2011;105:88-94.

34 van Weel C, Schellevis FG: Comorbidity and guidelines: conflicting interests. Lancet 2006;367:550-551. 